\title{
Tolerance to photoinhibition within lichen species is higher in melanised thalli
}

\author{
T.C. MAFOLE*, K.A. SOLHAUG**, F.V. MINIBAYEVA ${ }^{* * *}$ and R.P. BECKETT ${ }^{*,+}$ \\ School of Life Sciences, University of KwaZulu-Natal, Private Bag X01, Scottsville 3209, South Africa* \\ Faculty of Environmental Sciences and Natural Resource Management, Norwegian University of Life Sciences, \\ P.O. Box 5003, 1432 Ass, Norway ${ }^{* *}$ \\ Kazan Institute of Biochemistry and Biophysics, Federal Research Center "Kazan Scientific Center of RAS", \\ P.O. Box 30, Kazan 420111, Russia***
}

\begin{abstract}
Some lichenized ascomycetes synthesize melanic pigments when exposed to ultraviolet light and high solar radiation. Here, we used chlorophyll fluorescence in order to test the effect of melanisation on the ability of the lichens Cetraria islandica, Lobaria pulmonaria, Peltigera aphthosa, P. membranacea, Pseudocyphellaria gilva, and Sticta sublimbata to tolerate high-light stress. For each species, melanised and pale thalli were selected from relatively exposed and shaded individuals of the same population. For all species, melanised thalli displayed significantly less photoinhibition than pale thalli following a controlled exposure of hydrated thalli to high light. Melanised thalli were less photoinhibited than pale thalli in lichens from both high light and more shaded habitats, and those that possess either green-algal or cyanobacterial photobionts. Photoinhibition also occurred when dry lichens were exposed to high light; melanised thalli showed again less photoinhibition. Melanised thalli are less sensitive to the adverse effects of high light.
\end{abstract}

Additional key words: acclimation, desiccation, photoprotection, UV-B.

\section{Introduction}

Lichens represent a symbiosis between an ascomycete and one or more photosynthesizing algae or cyanobacteria, often with small amounts of basidiomycete yeasts (Spribille et al. 2016). Arguably, what makes lichens special, and what separates them from most other eukaryotic organisms, is their ability to tolerate extreme stress (Beckett et al. 2008). Lichens frequently grow in exposed microhabitats where they experience high light. In photosynthetic tissues, excessive solar radiation can cause a temporary or more permanent reduction of photosynthesis known as "photoinhibition". Photoinhibition is caused, directly or indirectly, by the stimulation of production of reactive oxygen species (ROS) that occurs when photosystems cannot use the light energy they are absorbing, and this energy rather activates oxygen (Gururani et al. 2015, Pospíšil 2016). The D1 protein, a key component of PSII, is believed to be the most sensitive to damage during photoinhibition. Some damage appears to occur even in moderate light intensities, therefore photo- synthesizing organisms must continuously repair the damage to this protein. The "PSII-repair cycle", occurring in chloroplasts and in cyanobacteria, involves degrading and re-synthesizing the $\mathrm{D} 1$ protein, followed by activation of the reaction center (Nath et al. 2013). Recent studies of photoinhibition have suggested that light-induced ROS formation causes most damage by inhibiting D1 protein repair, rather than directly affecting PSII (Nishiyama and Murata 2014). Irrespective of how it occurs, photoinhibition reduces the ability of lichen photobionts to photosynthesize. Strong evidence exists that photoinhibition regularly occurs in lichens in field situations (e.g., Leisner et al. 1997, Jairus et al. 2009, Míguez et al. 2017).

Plants possess a variety of mechanisms that help to overcome high light-induced photoinhibition. Some of these mechanisms involve reduction of ROS formation by converting excess light energy into thermal energy, a process termed nonphotochemical quenching (NPQ). Briefly, an increase in the gradient of protons across the thylakoid membrane triggers rearrangements and aggregation of LHCII and the formation of "NPQ quenchers". It has been

Received 30 October 2017, accepted 18 May 2018.

${ }^{+}$Corresponding author; e-mail: rpbeckett@gmail.com

Abbreviations: $\mathrm{BRI}$ - browning reflectance index; $\mathrm{F}_{\mathrm{M}}$ - maximum fluorescence; $\mathrm{F}_{\mathrm{M}}$ - maximal fluorescence yield of the light-adapted state; $F_{0}-$ minimal fluorescence yield of the dark-adapted state; $F_{t}-$ stable fluorescence signal in the light; $F_{V}-$ variable fluorescence or $\left(\mathrm{F}_{\mathrm{M}}-\mathrm{F}_{0}\right) ; \mathrm{F}_{\mathrm{V}} / \mathrm{F}_{\mathrm{M}}$ - maximal quantum yield of PSII photochemistry; NPQ - nonphotochemical quenching; ROS - reactive oxygen species; $\Phi_{\mathrm{PSII}}-$ effective quantum yield of PSII photochemistry or $\left(\mathrm{F}_{\mathrm{M}^{\prime}}-\mathrm{F}_{\mathrm{t}}\right) / \mathrm{F}_{\mathrm{M}^{\prime}}$.

Acknowledgements: The Research Council of Norway, South Africa-Norway, Research co-operation (SANCOOP), project 234178, is thanked for financial support. TCM and RPB thank the National Research Foundation (NRF) for additional financial support. FVM thanks the Russian Science Foundation, grant 18-14-00198, for partial financial support. Yngvar Gauslaa and Lusanda Matee are thanked for stimulating discussions and helpful comments on our manuscript. 
estimated that each unit of NPQ can protect against light of $c a .400 \mu \mathrm{mol}$ (photon) $\mathrm{m}^{-2} \mathrm{~s}^{-1}$ (Ruban 2016). However, NPQ is clearly a plastic character that varies between and within species, and increases with increasing ambient light (Gururani et al. 2015). Interestingly, recent evidence suggests that, unlike higher plants, photorespiration is not important for dissipating excess energy under excess light in algae, and therefore presumably is not important in lichens (Hanawa et al. 2017).

Although lichens possess some of the biochemical adaptions to high light, which are found in higher plants (e.g., Adams et al. 1993), they often respond to UV-B and high light by synthesizing cortical compounds (Solhaug and Gauslaa 2012). The most widespread cortical pigments are classic lichen substances, such as usnic acid, atranorin, and parietin (Solhaug and Gauslaa 2012). In some lichens, high light or UV induce the synthesis of a dark-coloured melanic pigments. There is little evidence that higher plants produce melanins in their leaves, although they may do so in their roots (Soares et al. 2011) or seeds (Al-Mufarrej et al. 2006). Rather, in higher plants, flavonoids appear to play the same role as melanins in lichens (Carletti et al. 2014). Melanin-producing lichens come from a range of lichen orders, and grow on a variety of substrata (Gauslaa and Solhaug 2001). There are few studies directly demonstrating that melanins protect lichens against photoinhibition. McEvoy et al. (2007) transplanted thalli of Lobaria pulmonaria to three sites with low, medium, and high light intensities for $100 \mathrm{~d}$. Lichens at the site with the highest light became significantly melanised. Thalli from each of these sites were then transplanted to a highlyexposed area for $12 \mathrm{~d}$. The melanised thalli displayed a much smaller reduction of $\mathrm{F}_{\mathrm{V}} / \mathrm{F}_{\mathrm{M}}$ than the material at the more shaded sites, strongly suggesting that melanins are involved in photoprotection. Further suggestion that melanins play protectives role came from the study of Färber et al. (2014) on pendulous lichens that dominate canopies of boreal forests. Typically, dark Bryoria species grow in the upper canopy, while pale Alectoria and Usnea species occupy the lower canopy. Exposing these lichens under controlled conditions to a light of $400 \mu \mathrm{mol}$ (photon) $\mathrm{m}^{-2} \mathrm{~s}^{-1}$ for $7 \mathrm{~d}$ caused much less photoinhibition in the melanised Bryoria species than that of the non-melanised Alectoria and Usnea. The main aim of the work presented was to systematically carry out within-species comparisons of the tolerance to photoinhibition in melanised and pale individuals of a range of lichens, including species with chlorophycean and cyanobacterial species, which grow in shaded or more light-exposed habitats.

A further aim of our study was to test whether melanisation is more effective in protecting dry or wet thalli. It is well known that lichens suffer from light stress even when desiccated (Kershaw and MacFarlane 1980). In bryophytes, desiccation apparently does not stop the transfer of excitation energy from the light-harvesting pigments to the reaction centers (Heber et al. 2006). Furthermore, no water is necessary for the formation of singlet oxygen from a chlorophyll triplet (Pospíśil 2106). It may be also relevant that changes in gene expression and/or protein synthesis have been observed in dry seeds of Nicotiana (Bove et al. 2005, Leubner-Metzger 2005) and Arabidopsis (Cadman et al. 2006, Chibani et al. 2006). These results have been interpreted as indicating the existence of hydrated pockets. Possibly, similar pockets in dry lichens allow ROS such as $\mathrm{H}_{2} \mathrm{O}_{2}$ to form when desiccated thalli are illuminated. Even if light only causes the formation of tiny amounts of ROS, in desiccated thalli, normal processes, which repair DNA and other biomolecules, do not take place (Buffoni-Hall et al. 2003). In L. pulmonaria, cortical transmittance to PAR is typically between one third and one half lower in the airdry compared to the hydrated state (Gauslaa and Solhaug 2001). Melanisation significantly reduces transmittance, and interestingly, the transmittance of the upper cortex of melanised thalli to PAR is about $40 \%$ lower than pale thalli when the thalli are dry, but only about $30 \%$ lower when the thalli are wet. We therefore hypothesized that melanisation may give a greater photoprotection when the thalli are air-dry.

\section{Materials and methods}

Plant material: Lichen material was collected from the localities listed below. For each species, melanised and pale thalli were selected from exposed and shaded individuals of the same population, never more than $5 \mathrm{~m}$ apart. If collected wet, material was slowly dried at room temperature. Material was stored at $-20^{\circ} \mathrm{C}$ until ready for experimentation for a maximum of two weeks. One day before each experiment, 2-cm discs were cut, or for small thalli, thallus fragments were selected. Lichens were stored overnight on wet filter paper in Petri dishes under dim light $\left[5 \mu \mathrm{mol}\right.$ (photon) $\left.\mathrm{m}^{-2} \mathrm{~s}^{-1}\right]$ at a cool temperature $\left(15^{\circ} \mathrm{C}\right.$, thermostatically controlled room). Before highlight treatment, chlorophyll (Chl) fluorescence parameters were measured, and then material was either slowly dried for $4 \mathrm{~h}$, or used immediately.

\begin{tabular}{llll}
\hline Species & Collection locality & Photobiont & Shade/sun species \\
\hline Cetraria islandica (L.) Ach. & Soil, Langangen, Norway & Chlorophycean & Sun \\
Lobaria pulmonaria (L.) Hoffm. & Oak trees, Langangen, Norway & Chlorophycean & Shade \\
Peltigera aphthosa (L.) Willd. & Soil, outskirts of Ås, Norway & Chlorophycean & Sun \\
Peltigera membranacea (Ach.) Nyl. & Soil, outskirts of Ås, Norway & Cyanobacterial & Sun \\
Pseudocyphellaria gilva (Ach.) Malme & Leucosidea sericea trees, Fort & Cyanobacterial & Shade \\
& Nottingham, RSA & Cyanobacterial & Shade \\
Sticta sublimbata (J.Steiner) Swinscow \& Krog & Leucosidea sericea trees, Fort & Nottingham, RSA & \\
\hline
\end{tabular}


Reflectance measurements to estimate melanin content: Reflectance spectra of the upper cortex were recorded on dry thalli as described by Solhaug et al. (2003). Briefly, an integrating sphere (model ISP-50-REFL OceanOptics, Eerbeek, The Netherlands) was pressed against the thalli, and thalli were then illuminated with a halogen lamp

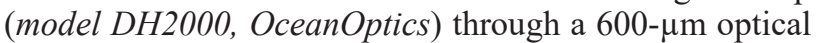
fibre (thick) connected to the input port of the integrating sphere. Reflectance (400-1,050 nm) was measured with a spectrometer (model SD2000, OceanOptics) connected to the output port of the sphere with a $400-\mu \mathrm{m}$ fibre. Reflection was calculated relative to a reference spectrum derived from a white reference tile (WS-2, OceanOptics). The browning reflectance index (BRI), calculated as $\left(1 / R_{550}-1 / R_{700}\right) / R_{750}$ (Solovchenko et al. 2001), was used as a quantitative estimate of melanic compounds.

Chl $\boldsymbol{a}$ fluorescence was measured using the red version of the PAM 2000 fluorimeter (Walz, Effeltrich, Germany). The maximal efficiency of PSII $\left(\mathrm{F}_{\mathrm{V}} / \mathrm{F}_{\mathrm{M}}\right)$ and the operating efficiency of PSII ( $\left.\Phi_{\text {PSII }}\right)$ were measured. Thalli were initially dark-adapted at room temperature for $10 \mathrm{~min}$. At the start of a run, a saturating flash was applied to determine $\mathrm{F}_{\mathrm{V}} / \mathrm{F}_{\mathrm{M}}$. Thalli were then exposed to PAR at $30 \mu \mathrm{mol}$ (photon) $\mathrm{m}^{-2} \mathrm{~s}^{-1}$ for $10 \mathrm{~min}$, after which fluorescence had reached a stable value. Another saturating flash was then applied, and $\mathrm{F}_{\mathrm{V}} / \mathrm{F}_{\mathrm{M}}$ and $\Phi_{\mathrm{PSII}}$ was calculated as:

$\mathrm{F}_{\mathrm{V}} / \mathrm{F}_{\mathrm{M}}=\left(\mathrm{F}_{\mathrm{M}}-\mathrm{F}_{0}\right) / \mathrm{F}_{\mathrm{M}}$

where $F_{M}$ is the maximum fluorescence (reaction centers closed) and $F_{0}$ is the minimum fluorescence (reaction centers open), and:

$\Phi_{\text {PSII }}=\left(F_{M^{\prime}}-F_{t}\right) / F_{M}$,

where $F_{t}$ is the stable fluorescence signal in the light, and $F_{M}$, is the maximum fluorescence at saturating light intensity pulse.

High-light stress was applied by a white LED lightsource panel (Model SL-3500, Photon System Instruments, Brno, Czech Republic). Light was set at 800 or $1,500 \mu \mathrm{mol}\left(\right.$ photon) $\mathrm{m}^{-2} \mathrm{~s}^{-1}$ until the maximum quantum yield of PSII photochemistry $\left(\mathrm{F}_{\mathrm{V}} / \mathrm{F}_{\mathrm{M}}\right)$ was reduced from values of around 0.7 to $0.3-0.4$, with each species needing different times as indicated in Table 1.

Chl fluorescence measurements were made in moist material before high-light treatment ("time zero"), at the end of the high-light treatment, and then at intervals for up to $40 \mathrm{~h}$. Photoinhibition in thalli exposed to high light in the dry state was measured at intervals following the hydration of replicate samples. When sufficient inhibition had occurred, they were immediately hydrated following exposure by being placed on moist filter paper and then sprayed with additional distilled water. During recovery, lichens were maintained at room temperature $\left(20^{\circ} \mathrm{C}\right)$ and dim light $\left[5 \mu \mathrm{mol}\right.$ (photon) $\mathrm{m}^{-2} \mathrm{~s}^{-1}$ ] as recommended by Solhaug (2018).

Results were analyzed using a two-way analysis of variance (ANOVA, Microsoft Excel), with melanisation and time as the two factors.

\section{Results}

Lichens were more tolerant to high light when dry; compared to wet thalli, much longer exposures were needed to create similar photoinhibition (Table 1). In general, lichens collected from open habitats required longer times or high light levels to create similar levels of photoinhibition compared to species from more shaded localities.

Measurement of thallus reflection indicated that the extent of melanisation varied greatly between different lichen species (Table 2). For example, in Pseudocyphellaria gilva, the BRI of melanised thalli was only $20 \%$ higher than that of pale thalli, while in Cetraria islandica, the BRI was more than one hundred times greater (Table 2).

Initial values of $\mathrm{F}_{\mathrm{V}} / \mathrm{F}_{\mathrm{M}}$ and $\Phi_{\mathrm{PSII}}$ were very similar in melanised and pale thalli (Figs. 1-3). In most cases, $24 \mathrm{~h}$ after the photoinhibitory stress, almost all lichens fully recovered, although the recovery was not complete in some cases, e.g., non-melanised $C$. islandica (Fig. $1 B, D$ ), wet Peltigera membranacea (Fig. 2E,F) and Pseudocyphellaria gilva (Fig. $3 B$ ). In all cases, melanised thalli showed significantly lesser photoinhibition than that of pale thalli in both wet and dry thalli. The differences between melanised and pale thalli were the greatest in those species that showed the greatest relative increases in BRI between pale and melanised thalli. For example, the greatest difference between melanised and pale thalli was in C. islandica (Fig. 1A-D), the species that showed the greatest increase in BRI (Table 2). By contrast, melanised thalli of Pseudocyphellaria and Sticta had BRI values only slightly greater than those of pale thalli, and in these two species, melanised thalli displayed only small (but

Table 1. Light intensity and time of exposure used to induce photoinhibition.

\begin{tabular}{lllll}
\hline Species & $\begin{array}{l}\text { Dry } \\
\text { Time }[\mathrm{h}]\end{array}$ & Light intensity $\left[\mu \mathrm{mol} \mathrm{m}^{-2} \mathrm{~s}^{-1}\right]$ & Time $[\mathrm{h}]$ & Light intensity $\left[\mu \mathrm{mol} \mathrm{m}^{-2} \mathrm{~s}^{-1}\right]$ \\
\hline Cetraria islandica & 36 & 800 & 3 & 1,500 \\
Lobaria pulmonaria & 12 & 800 & 8 & 800 \\
Peltigera aphthosa & 12 & 800 & 5 & 1,500 \\
Peltigera membranacea & 12 & 800 & 12 & 800 \\
Pseudocyphellaria gilva & 6 & 800 & 5 & 800 \\
Sticta sublimbata & 4 & 800 & 2 & 800 \\
\hline
\end{tabular}


Table 2. Browning reflectance index (BRI) of the lichens used in this study. Figures are given $\pm 1 \mathrm{SD}, n=12$. BRI was calculated as described by Solovchenko et al. (2001).

\begin{tabular}{llcc}
\hline Species & BRI & BRI & \\
& Non-melanised thalli & Melanised thalli & Increase in BRI in melanised thalli \\
\hline Pseudocyphellaria gilva & $7.5 \pm 1.9$ & $9.3 \pm 1.9$ & 1.2 \\
Sticta sublimbata & $8.2 \pm 2.6$ & $24.8 \pm 4.0$ & 3.0 \\
Lobaria pulmonaria & $4.4 \pm 1.1$ & $48.4 \pm 42.4$ & 11.0 \\
Peltigera membranacea & $2.8 \pm 0.5$ & $31.6 \pm 4.1$ & 11.3 \\
Peltigera aphthosa & $2.1 \pm 2.1$ & $24.8 \pm 15.6$ & 11.8 \\
Cetraria islandica & $0.6 \pm 0.8$ & $87.9 \pm 27.1$ & 146.5 \\
\hline
\end{tabular}

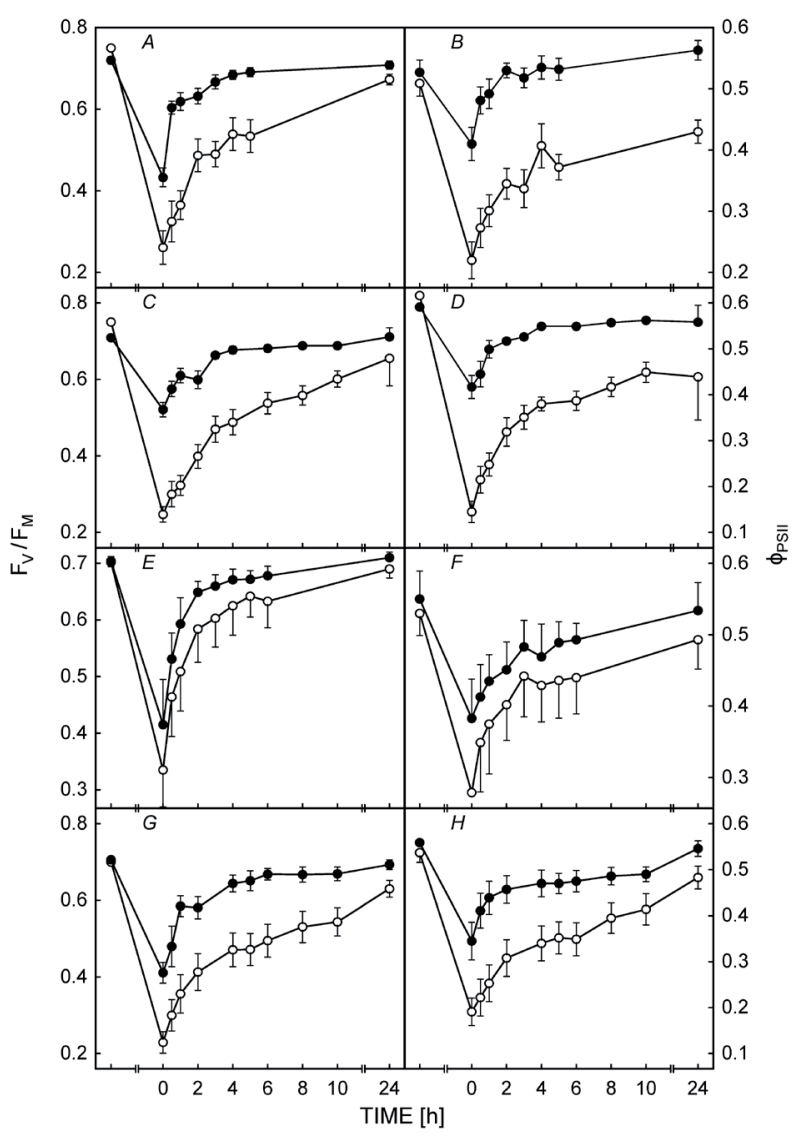

Fig. 1. The effect of melanisation on the recovery of $F_{V} / F_{M}$ and $\Phi_{\mathrm{PSII}}$ from a photoinhibitory exposure to light in Cetraria islandica $(A-D)$ and Lobaria pulmonaria $(E-H)$. For this experiment, and those that follow, the exposure time and light levels are given in Table 1. The initial data points are the values in freshly collected, hydrated material. Open symbols indicate non-melanised thalli, while solid symbols represent melanised. $A$ and $E$ are results for $\mathrm{F}_{\mathrm{V}} / \mathrm{F}_{\mathrm{M}}$ for wet material, $B$ and $F$ indicate $\Phi_{\mathrm{PSII}}$ for wet material, $C$ and $G$ are data for $\mathrm{F}_{\mathrm{V}} / \mathrm{F}_{\mathrm{M}}$ for dry material, and $D$ and $H$ indicate $\Phi_{\text {PSII }}$ for wet material. Data is given \pm SE of the mean, $n=15$. Error bars smaller than the size of the symbols are omitted.

significant) improvements in recovery after high-light stress (Fig. 3). In general, $\Phi_{\text {PSII }}$ appeared to be a more sensitive indicator of recovery from photoinhibition than $\mathrm{F}_{\mathrm{V}} / \mathrm{F}_{\mathrm{M}}$. For example, in C. islandica, $\mathrm{F}_{\mathrm{V}} / \mathrm{F}_{\mathrm{M}}$ indicated that after $24 \mathrm{~h}$ pale thalli completely recovered from photoinhibition (Fig. $1 A, C$ ), while $\Phi_{\text {PSII }}$ measurements showed that recovery was incomplete (Fig. $1 B, D$ ).

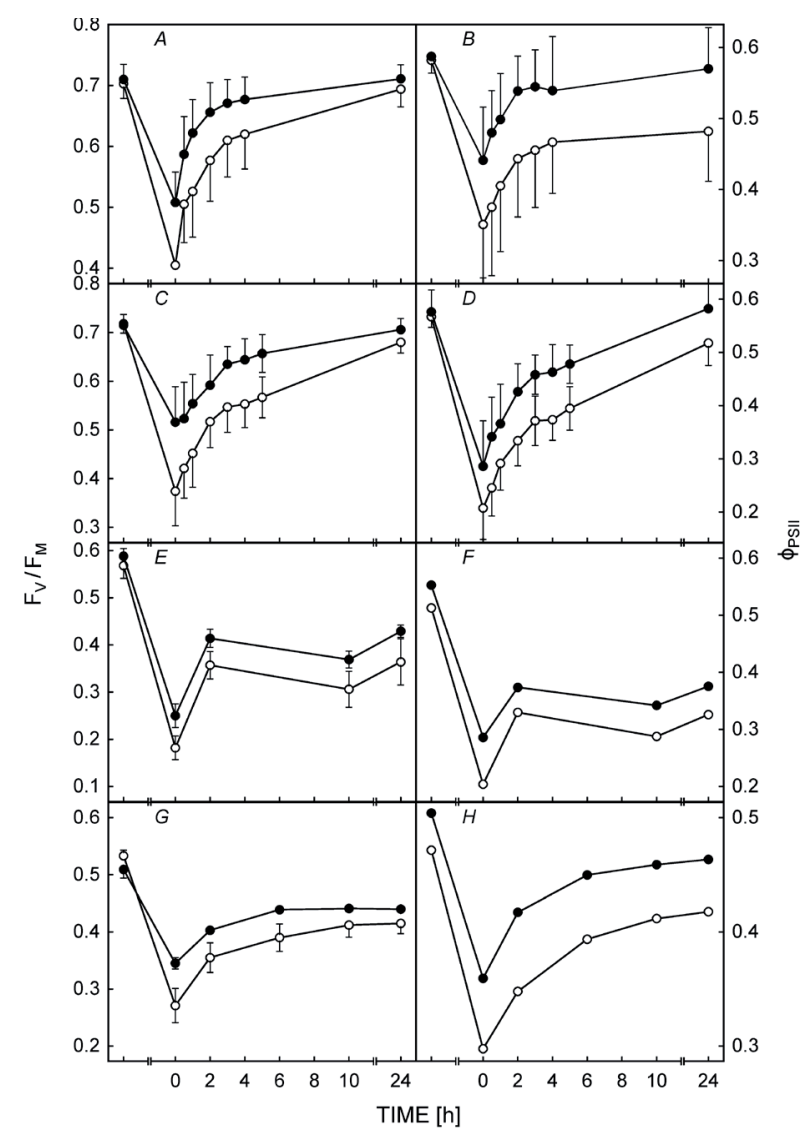

Fig. 2. The effect of melanisation on the recovery of $F_{V} / F_{M}$ and $\Phi_{\mathrm{PSII}}$ from a photoinhibitory exposure to light in Peltigera aphthosa $(A-D)$ and $P$. membranacea $(E-H)$.

\section{Discussion}

The main conclusion of the work presented here is that melanised lichens are more tolerant to photoinhibition than the pale thalli, for both desiccated and hydrated thalli. Apart from the field experiment of McEvoy et al. (2007) with just one species (Lobaria pulmonaria), the present study is the first to directly correlate within-species melanisation to increases in tolerance to photoinhibition in lichen photobionts. In general, the greatest differences in the effects and rate of recovery from high light occurred in species with the largest difference in BRI between melanised and pale thalli. For example, $C$. islandica had the largest difference in BRI between pale and melanised 


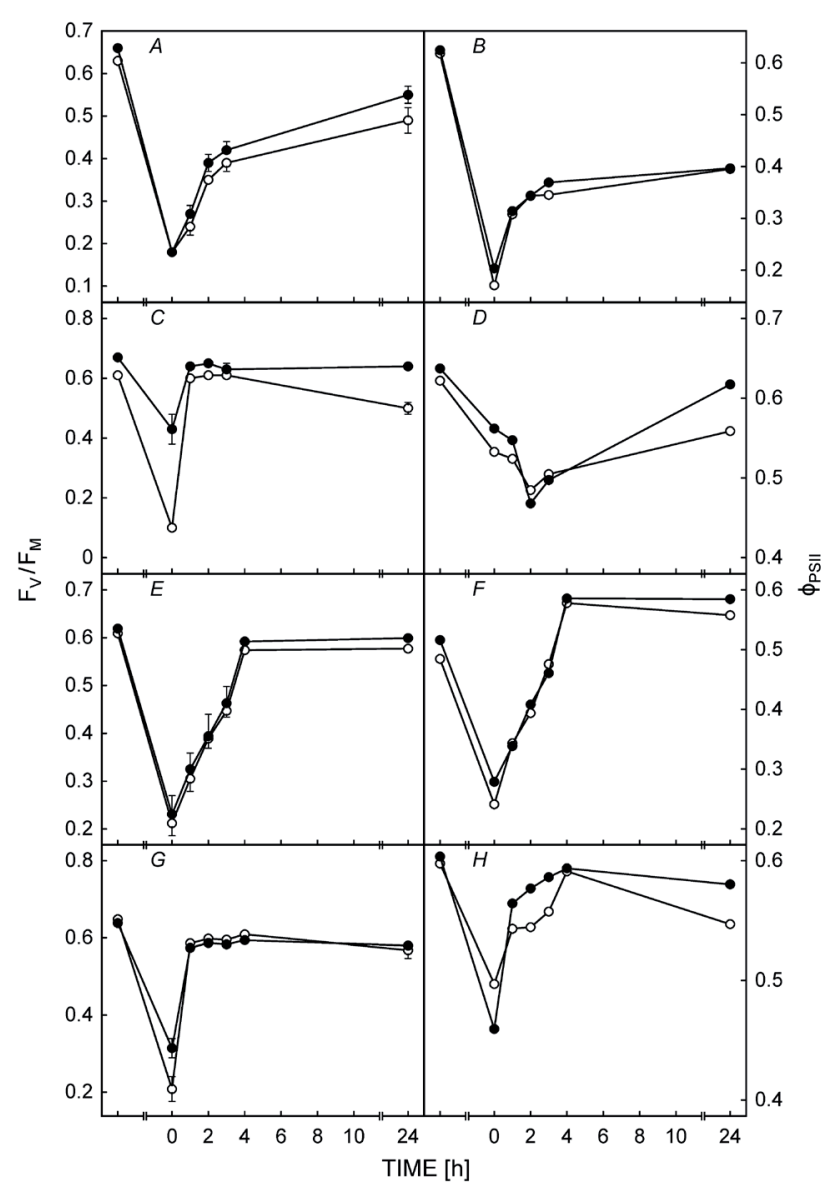

Fig. 3. The effect of melanisation on the recovery of $\mathrm{F}_{\mathrm{V}} / \mathrm{F}_{\mathrm{M}}$ and $\Phi_{\mathrm{PSII}}$ from a photoinhibitory exposure to light in Pseudocyphellaria gilva $(A-D)$ and Sticta sublimata $(E-H)$.

thalli (Table 2), and also displayed the largest difference in the effects of high-light stress (Fig. 1A-D). By contrast, for species in which differences in BRI were lesser, e.g., Pseudocyphellaria gilva and Sticta sublimbata (Table 2), the differences in the effects of high-light stress were much lesser (Fig. 3). An inherent problem with the approach used here is that although melanised and pale thalli were collected only a few meters apart, the melanised thalli probably had a history of exposure to higher light levels in contrast to pale thalli. As a result, melanised thalli might therefore possess some of the biochemical mechanisms that confer tolerance to photoinhibition, e.g., increased NPQ. In theory, we could have produced melanic and non-melanic thalli by using UV-transmitting and UVabsorbing screens as in our earlier work (e.g., Mafole et al. 2017). However, the problem would remain as melanin synthesis would cause differential screening of the algae, and therefore possibly induction of alternative mechanism that protect the photosynthetic apparatus. In future, we plan to attempt to separate the effects of melanisation from biochemical mechanisms, for example by removing a melanised or non-melanised cortex and directly exposing the underlying algal layer (see Gauslaa et al. 2017 for how this might be done). However, results presented here clearly show that, compared to pale thalli, melanised thalli in species, which grow in both high and more shaded habitats and which possess either green or cyanobacterial photobionts, have significantly greater tolerance to photoinhibition, strongly suggesting that melanins play a key role in photoprotection.

Melanised lichens are more resistant to photoinhibition than the pale ones: Melanins are probably important for mycobiont and photobiont symbionts for different reasons. The fungal symbiont is responsible for melanin synthesis, and the trigger for synthesis is UV light (Matee et al. 2016). Fungi apparently need more protection from UV than the photobionts, as elevated UV affects overall lichen growth more than purely photobiont responses, such as Chl content and the quantum yield of photosynthesis (Chowdhury et al. 2017). Photobionts in vivo avoid UV levels currently being experienced by lichens in the field, as even in pale thalli the cortex effectively blocks transmittance of light with wavelengths lesser than 325 nm (Gauslaa et al. 2017). However, while not needing UV protection, results presented here show that in melanised thalli, the photobiont are more tolerant to photoinhibition by high PAR. Therefore, although the mycobiont benefits directly from melanin synthesis by having increased UV protection, protecting the photobionts from high PAR indirectly benefits the mycobiont by increasing the supply of photosynthates to the whole thallus.

Dry melanised lichens are also more tolerant to high light than pale thalli: For both wet and dry thalli, melanised thalli are more tolerant to photoinhibition than the pale ones (Figs. 1-3). All species were highly desiccation tolerant, and when not photoinhibited completely, they recovered from desiccation very quickly during rehydration (data not shown). However, some of the recovery that occurs during the first $30 \mathrm{~min}$, when photoinhibited dry lichens are rehydrated, undoubtedly represents recovery from desiccation stress. While lichens are more tolerant of light stress when dry, they eventually become photoinhibited when exposed to even moderate light intensities (Table 1). This is perhaps surprising, as at low thallus water contents metabolism is almost inactive, presumably reducing lightinduced ROS formation and the resulting photoinhibition. Furthermore, the cortical transmittance to PAR is much lower (between one third and one half lower) in air-dry compared with hydrated thalli (Gauslaa and Solhaug 2001), probably in part because desiccation enhances light scattering, lengthening the path of the light in the cortex, and thereby increasing the absorption by melanins. While more research is needed to understand the mechanism of photoinhibition in dry lichens, recovery may take many hours (Figs. 1-3), reducing carbon fixation for the symbiosis. Interestingly, comparing wet and dry lichens, melanisation is sometimes more effective at preventing photoinhibition when thalli are dry (e.g., compare Fig. $1 F$ with $1 G$, Fig. $3 A$ with $3 C$ and Fig. $3 E$ with $3 G$ ). One explanation for this result is that melanisation has different effects on cortical transmittance in wet and dry lichens. While in wet thalli the transmittance of the upper cortex of melanised thalli of L. pulmonaria to PAR 
is about $30 \%$ lower than that of pale thalli, in dry thalli, the reduction is about 40\% (Gauslaa and Solhaug 2001). Assuming a similar difference occurs in other lichens, a greater reduction in cortical transmittance when lichens are dry thalli may explain why melanisation can be more effective at reducing photoinhibition in these thalli.

$\Phi_{\mathrm{PSII}}$ can be a more sensitive indicator of photoinhibition than $\mathbf{F}_{\mathbf{V}} / \mathbf{F}_{\mathbf{M}}$ : Results presented here suggest that for some lichens, measuring the operating efficiency of PSII $\left(\Phi_{\mathrm{PSII}}\right)$ can give a more sensitive measure of the effects of high-light stress than simply measuring maximum quantum yield of PSII photochemistry $\left(\mathrm{F}_{\mathrm{V}} / \mathrm{F}_{\mathrm{M}}\right) . \mathrm{F}_{\mathrm{V}} / \mathrm{F}_{\mathrm{M}}$ can be quickly and easily measured, and is therefore commonly used in photoinhibition studies (e.g., Míguez et al. 2017, Solhaug 2018). However, $\Phi_{\text {PSII }}$ can be also readily derived from $\mathrm{Chl}$ fluorescence measurements. Measurement of $\Phi_{\mathrm{PSII}}$ takes longer than that of $\mathrm{F}_{\mathrm{V}} / \mathrm{F}_{\mathrm{M}}$, as an actinic light must be switched on and fluorescence must reach a stable value $\left(F_{t}\right)$ before a saturating pulse is given and $F_{m}$, measured. However, in the present study, in both wet and dry non-melanised C. islandica (Fig. 1) and wet Pseudocyphellaria gilva (Fig. 3) simply measuring $\mathrm{F}_{\mathrm{V}} / \mathrm{F}_{\mathrm{M}}$ would indicate that lichens almost completely recovered from photoinhibition (Fig. $1 A, C$; Fig. $3 A$ ), while $\Phi_{\mathrm{PSII}}$ shows that some residual effects remained (Fig. 1B, $C$; Fig. $3 B$ ). In general, for all species tested, $\Phi_{\mathrm{PSII}}$ measurements show more clearly that melanised thalli recover faster and more fully from photoinhibition than $\mathrm{F}_{\mathrm{V}} / \mathrm{F}_{\mathrm{M}}$. Therefore, although more time consuming to measure, $\Phi_{\text {PSII }}$ can be a more sensitive indicator of high-light stress.

Conclusion: Results presented here clearly show that melanised thalli are more tolerant to high light than pale ones. As discussed in the Introduction, melanisation is not the only mechanism of photoprotection, and more work is needed to compare the importance and efficiency of melanisation with, for example, other lichen secondary metabolites and biochemical adaptations such as quenching. Melanisation may not invariably be beneficial for lichens. Mafole et al. (2017) recently showed that melanised thalli of Lobaria pulmonaria are disadvantaged if light levels fall below about $100 \mu \mathrm{mol}\left(\right.$ photon) $\mathrm{m}^{-2} \mathrm{~s}^{-1}$, due to reduced light interception by the photobionts. Falling light levels may occur for several reasons, e.g., reductions in light availability during autumn, development of leaves in branches above lichens or by the growth of plants surrounding the host tree. A further potential disadvantage of melanisation is that it increases thallus temperature by up to $3{ }^{\circ} \mathrm{C}$ (McEvoy et al. 2007), possibly inducing heat stress. However, if light levels remain high, in the field, melanised thalli are likely to spend significantly less time photoinhibited, which could promote productivity of the whole thallus.

\section{References}

Adams W.W. III, Demmig-Adams B., Lange O.L.: Carotenoid composition and metabolism in green and blue-green algal lichens in the field. - Oecologia 94: 576-584, 1993.
Al-Mufarrej S.I., Hassib A.M., Hussein M.F.: Effect of melanin extract from black cumin seeds (Nigella sativa L.) on humoral antibody response to sheep red blood cells in albino rats. $-\mathrm{J}$. Appl. Anim. Res. 29: 37-41, 2006.

Beckett R.P., Kranner I., Minibayeva F.V.: Stress physiology and the symbiosis. - In: Nash T.H. (ed.): Lichen Biology, $2^{\text {nd }}$ ed. Pp. 136-153. Cambridge University Press, Cambridge 2008.

Bove J., Lucas P., Godin B. et al.: Gene expression analysis by cDNA-AFLP highlights a set of new signaling networks and translational control during seed dormancy breaking in Nicotiana plumbaginifolia. - Plant Mol. Biol. 57: 593-612, 2005.

Buffoni Hall R.S., Paulsson M., Duncan K. et al.: Water- and temperature-dependence of DNA damage and repair in the fruticose lichen Cladonia arbuscular ssp. mitis exposed to UV-B radiation. - Physiol. Plantarum 118: 371-379, 2003.

Cadman C.S.C, Toorop P.E., Hilhorst H.W.M. et al.: Gene expression profiles of Arabidopsis Cvi seeds during dormancy cycling indicate a common underlying dormancy control mechanism. - Plant J. 46: 805-822, 2006.

Carletti G., Nervo G., Cattivelli L.: Flavonoids and melanins: a common strategy across two kingdoms. - Int. J. Biol. Sci. 10: 1159-1170, 2014.

Chibani K., Ali-Rachedi S., Job C. et al.: Proteomic analysis of seed dormancy in Arabidopsis. - Plant Physiol. 142: 14931510, 2006.

Chowdhury D.P., Solhaug K.A., Gauslaa Y.: Ultraviolet radiation reduces lichen growth rates. - Symbiosis 73: 27-34, 2017.

Färber L., Solhaug K.A., Esseen P.-A. et al.: Sunscreening fungal pigments influence the vertical gradient of pendulous lichens in boreal forest canopies. - Ecology 95: 1464-1471, 2014.

Gauslaa Y., Alam M.A., Lucas P.-L. et al.: Fungal tissue per se is stronger as a UV-B screen than secondary fungal extrolites in Lobaria pulmonaria. - Fungal Ecol. 26: 109-113, 2017.

Gauslaa Y., Solhaug K.A.: Fungal melanins as a sun screen for symbiotic green algae in the lichen Lobaria pulmonaria. Oecologia 126: 462-471, 2001.

Gururani M.A., Venkatesh J., Tran L.-S.P.: Regulation of photosynthesis during abiotic stress induced photoinhibition. - Mol. Plant 8: 1304-1320, 2015.

Hanawa H., Ishizaki K., Nohira K. et al.: Land plants drive photorespiration as higher electron-sink: comparative study of post-illumination transient $\mathrm{O}_{2}$-uptake rates from liverworts to angiosperms through ferns and gymnosperms. - Physiol. Plantarum 161: 138-149, 2017

Heber U., Bilger W, Shuvalov, V.A.: Thermal energy dissipation in reaction centres and in the antenna of photosystem II protects desiccated poikilohydric mosses against photooxidation. - J. Exp. Bot. 57: 2993-3006, 2006.

Jairus K., Löhmus A., Löhmus P.: Lichen acclimatization on retention trees: a conservation physiology lesson. - J. Appl. Ecol. 46: 930-936, 2009.

Kershaw K.A., MacFarlane J.D.: Physiological-environmental interactions in lichens. X. Light as an ecological factor. - New Phytol. 84: 687-701, 1980.

Leisner J.M.R., Green T.G.A., Lange O.L.: Photobiont activity of a temperate crustose lichen: long-term chlorophyll fluorescence and $\mathrm{CO}_{2}$ exchange measurements in the field. Symbiosis 23: 165-182, 1997.

Leubner-Metzger G.: $\beta-1,3$-Glucanase gene expression in lowhydrated seeds as a mechanism for dormancy release during tobacco after-ripening. - Plant J. 41: 133-145, 2005.

Mafole T.C., Chiang C., Solhaug K.A. et al.: Melanisation in the old forest lichen Lobaria pulmonaria (L) Hoffm. reduces the efficiency of photosynthesis. - Fungal Ecol. 29: 103-110, 2017.

Matee L.P., Beckett R.P., Solhaug K.A. et al.: Characterization 
and role of tyrosinases in the lichen Lobaria pulmonaria (L) Hoffm. - Lichenologist 48: 311-322, 2016.

McEvoy M., Gauslaa Y., Solhaug K.A.: Changes in pools of depsidones and melanins, and their function, during growth and acclimation under contrasting natural light in the lichen Lobaria pulmonaria. - New Phytol. 175: 271-282, 2007.

Míguez F., Fernández-Marín B., Becerril J-M. et al.: Diversity of winter photoinhibitory responses: a case study in co-occurring lichens, mosses, herbs and woody plants from subalpine environments. - Physiol. Plantarum 160: 282-296, 2017.

Nath K., Jajoo A., Poudyal R.S. et al.: Towards a critical understanding of the photosystem II repair mechanism and its regulation during stress conditions. - FEBS Letters $\mathbf{5 8 7}$ : 3372-3381, 2013.

Nishiyama Y., Murata N.: Revised scheme for the mechanism of photoinhibition and its application to enhance abiotic stress tolerance of the photosynthetic machinery. - App. Microbiol. Biot. 98: 8777-8796, 2014.

Pospíšil P.: Production of reactive oxygen species by photosystem II as a response to light and temperature stress. - Front. Plant Sci. 7: 1950, 2016.

Ruban A.V.: Nonphotochemical chlorophyll fluorescence quenching: Mechanism and effectiveness in protecting plants from photodamage. - Plant Physiol. 170: 1903-1916, 2016.

Soares A.R., de Lourdes Lucio Ferrarese M., de Cássia SiqueiraSoares R. et al.: The allelochemical L-DOPA increases melanin production and reduces reactive oxygen species in soybean roots. - J. Chem. Ecol. 37: 891-898, 2011.

Solhaug K.A.: Low-light recovery effects on assessment of photoinhibition with chlorophyll fluorescence in lichens. Lichenologist 50: 139-145, 2018.

Solhaug K.A., Gauslaa Y.: Secondary lichen compounds as protection against excess solar radiation and herbivores. Prog. Bot. 73: 283-304, 2012.

Solhaug K.A., Gauslaa Y., Nybakken L. et al:: UV-induction of sun-screening pigments in lichens. - New Phytol. 158: 91$100,2003$.

Solovchenko A.E., Chivkunova O.B., Merzlyak M.N. et al.: A spectrophotometric analysis of pigments in apples. - Russ. J. Plant Physl+ 48: 693-700, 2001.

Spribille T., Tuovinen V., Resl P. et al.: Basidiomycete yeasts in the cortex of ascomycete macrolichens. - Science 353: 488492, 2016.

(C) The authors. This is an open access article distributed under the terms of the Creative Commons BY-NC-ND Licence. 